\title{
Feed extrusion process description
}

\author{
Galen J. Rokey ${ }^{1}$, Brian Plattner ${ }^{1}$, Edivaldo M. de Souza ${ }^{1}$ \\ ${ }^{1}$ Wenger Mfg. Inc. -Technical Center - 714 Main Street - Sabetha - Kansas - USA.
}

ABSTRACT - The following work discusses the main features of feed extrusion process explaining the expected effects on the final product according to the raw material used as starch, protein, fat and fiber. The selection of processing equipments as feeder, preconditioner and extruder is discussed considering the involved costs and the probability of future expansion. Dryers are also essential in the extrusion process as it reduces the level of moisture in an extrusion cooked product. High moisture levels increase the water activity which favors the bacterial and mold growth so an overview of different kinds of dryers is considered. Guidelines for an economic prediction are shown to determine the potential for profit considering the input of raw material cost, energy cost and capital equipment cost as related to the extrusion module.

Key Words: extruder, extrusion process, feed extrusion, livestock feed, pet food

\section{Descrição do processo de extrusão do alimento}

RESUMO - Este trabalho aborda as principais características do processo de extrusão de alimentos, explicando os efeitos esperados no produto final, em função do tipo de componente utilizado na receita, como amido, proteínas, gorduras e fibras. O dimensionamento dos equipamentos da linha de extrusão, como silo, pré-condicionador e extrusor, é tratado considerando-se os custos envolvidos e a possibilidade de expansões futuras. Secadores também são essenciais no processo de extrusão, pois reduzem o nível de umidade do produto final. Altos níveis de umidade aumentam a atividade de água, favorecendo a proliferação de bactérias e mofo, portanto, uma visão geral de diferentes tipos de secadores é considerada. Orientações para uma previsão econômica são apresentadas para se determinar o potencial de lucro, considerando-se os custos com a matéria-prima, a energia utilizada no processo de fabricação e os equipamentos relacionados ao módulo de extrusão.

Palavras-chave: alimentos para animais de compania, extrusão do alimento, extrusor, processo de extrusão, ração animal

\section{Introduction}

\section{Process description for feed extrusion}

Commercial extrusion processing of food and feed products has been practiced for over 60 years. The screw extruder was first used as a continuous cooking device in the late 1930's. The first commercial application of this extrusion cooking process was in the mid 1940's. The end product was direct-expanded corn meal snacks. Today, the extrusion cooker has become the primary continuous cooking apparatus in the commercial production of most dry pet foods and aquatic feed and some applications for livestock feed.

Dry-expanded pet foods were first produced by extrusion cookers in the 1950's. The dry expanded pet food market since its introduction has grown into the largest annual production tonnage for extrusion cooking in the United States and around the world. The principles of producing pet foods through extrusion processing apply to most commercial animal feed, such as livestock and aquatic.

\section{Raw material characteristics and selection}

Raw ingredient formulation, selection of process equipment, and processing conditions are independent regions of control that may be exercised in the extrusion cooking of pet foods, aquatic and livestock feed. Although the control regions are independent, they are interrelated to the point that discussion of one must include the others. In this section, the subject of ingredient selection and how ingredients react to various extrusion processing conditions are addressed.

Raw material utilization and cost effective formulation are key operational factors. The ability to alter processing conditions and raw material formulations to keep formulation costs at a minimum while maintaining high quality standards and minimum operating costs is a challenge for every processor. 
Ingredient selection has a tremendous impact on final product texture, uniformity, extrudability, nutritional quality, and economic viability. Within certain limits set by a nutritionist, the extrusion cooking process can produce a wide range of products. In general, during the extrusion cooking of cereal grain and protein blends, the moistened granular or floury materials are converted into dough. The starchy components gelatinize, resulting in a substantial uptake of moisture and an increase in dough viscosity. Some protein constituents may impact elasticity properties that are characteristic of hydrated and developed glutinous dough. Other proteinaceous materials, those with low protein solubility such as meat meal or fish meal, may contribute less to the adhesive and stretchable functional properties.

Starch

Starch is the primary carbohydrate found in pet foods, aquatic and livestock feed. Starch levels can vary from as little as five percent to as much as 60 percent of the formulation. When gelatinization occurs during extrusion cooking, starch becomes soluble and absorbs large quantities of water. Starch is an important source of energy in pet foods and livestock feed. Many studies have proven that dogs cannot digest raw starch. As early as 1979 Teeter indicated that raw starch diets can result in diarrhea.

Starch also contributes to both expansion and binding in the final product, especially important for aquatic feed. The amylose fraction of starch has greater binding properties than the amylopectin fraction. Tuber starches such as potato and tapioca, which are high in amylase, are the best choices for binders to improve cohesion of the final product. Pre-cooked starches are sometimes utilized in formulations, although their higher costs often limit their use.

Starch levels in the final product are dictated by nutritional requirements and the desired bulk density. Increasing the starch content can aid in decreasing the bulk density of extruded products. Starch levels of 30 percent in cat and puppy foods and 40 percent in dry expanded dog foods are typical. Sinking aquatic feed requires at least $10 \%$ good quality starch; floating aquatic feeds requires a minimum of $20 \%$ starch in the formula.

\section{Protein}

When formulating and processing pet foods, livestock and aquatic feed by extrusion cooking, it is important to understand that cereal grains alone cannot provide the required amino acid balance for proper growth and body maintenance. Therefore, proteinaceous ingredients serve to ensure nutritional complete diets. Proteinaceous ingredients often comprise 25 to 70 percent of the formulation. Proteins are often divided into plant and animal sources.

Plant protein sources include soybean meal, wheat gluten, and corn gluten meal. These vegetable proteins contribute greatly to both the structural and nutritional aspects of pet foods, aquatic and livestock feed. Due to their low heat treatment they have good "functional" properties and assist with expansion and binding during extrusion. They may be used as a protein source in formulating a feed or may be processed directly to serve as meat extenders in dry and canned pet foods. Vegetable protein sources can not be exclusively used in pet foods as they do not provide all of the essential amino acids.

Animal proteins generally do not contribute structurally to extrusion cooked feed. During their preparation they are often subjected to a high degree of thermal processing which renders than "nonfunctional." The exception would be products that are used in their fresh form or are processed in a manner to preserve the protein solubility such as spray dried blood meal. The addition of animal protein sources in a formulation allows a complete amino acid profile to be provided. The most common sources of animal proteins include fresh meat, poultry byproduct meal, fish meal, meat and bone meal, blood meal, and gelatin. Fat

Fats or lipids are an excellent source of energy in extruded products. Fat levels can exceed 30 percent but usually comprise less than 20 percent of the complete recipe. If extrusion is carried out at low moistures ( $<20$ percent) and high temperatures $\left(>150^{\circ} \mathrm{C}\right.$ ), it is quite likely that lipid/starch and lipid/protein complexes will be formed. Free fatty acids and polar lipids are especially reactive in these situations. Fat analysis of extruded products must include acid hydrolysis and not the Soxhlet method only, since the Soxhlet method is not capable of breaking down these complexes. However, the lipidbinding occurring during extrusion does not impair digestion when consumed.

The level of fat added during extrusion processing can affect the final product characteristics. Not only the level of fat, but also the source of fat has an effect on the expansion rate during extrusion. Indigenous fats, which are supplied as a component of a particular ingredient, tend to have less effect on expansion than fats added in their refined form. For example, a 15 percent fat formula where the fat is supplied through full fat canola as a component of that formulation has less effect on expansion than pure canola oil added to provide the same final fat level in the product. 
Heating fat sources to 40 to $60^{\circ} \mathrm{C}$ prior to blending with the balance of the formulation will minimize temperaturedependent viscosity changes, assist in the cooking of the total product, and reduce the expansion-depressing effect. Fat sources include tallow, poultry fat, vegetable oils, marine oils, and various blends from all sources.

Fiber

Reduced-calorie pet foods for obese or inactive pets are becoming common in the marketplace. These diets contain significant levels of cellulose and hemicellulose. Extrusion conditions are rarely severe enough to affect the apparent digestibility of dietary fiber. However, fibrous ingredients possess bulk densities and hydration properties quite different from traditional ingredients and require different extruder configurations and processing conditions. Cereal by-products are also largely used for filling on livestock and aquatic diets. Normally these by-products contains a good quantity of Fiber

High levels of fibrous ingredients tend to disrupt the continuous carbohydrate matrix of the extruded product resulting in a rough appearance and excessive fines. The starch contents of some fibrous ingredients such as wheat or rice bran can vary from 16 to 40 percent depending upon the variety, growing conditions, and milling properties of the grain. The variable starch levels can dramatically affect the extrusion process.

\section{Minor ingredients}

Vitamins are an important category of minor ingredients. Each vitamin has its own characteristic behavior during thermal processing, and some are unstable during storage. Vitamin stability during extrusion cooking is affected by moisture, pressure, shear, and temperature. Fat soluble vitamins, which include vitamins $\mathrm{A}, \mathrm{D}$, and $\mathrm{E}$, are fairly stable during extrusion, although 15 to 20 percent losses have been experienced.

The extrusion moisture level has the single greatest effect on vitamins retained. As a general rule, higher moisture levels yield more vitamins retained. The following options should be considered to maintain a recommended vitamin level in pet food products:

1. Use overages: It is recommended to use overages to compensate for losses occurring during storage and processing.

2. Use heat stable forms: Silicon or gelatin encapsulated forms, may be used to improve heat stability. Recent improvements in ascorbic acid stability (Stay-C ${ }^{\circledR}$ ) have reduced the need for expensive overages.

3. Adding vitamins with topical coatings such as fat: Vitamin-fortified fat can be sprayed on extruded and dried pet foods. This practice is quite effective in maintaining stability even during subsequent storage. However, if the heated fat is held for extended periods at elevated temperature, the vitamin losses can be extensive.

It may be desirable to include flavor enhancers to improve palatability. Palatability enhancers include animal fat (tallow, lard or poultry fat), liquid meat extracts, dextrin materials, vegetable or fish oils, animal fat extracts, lipolyzed beef tallow, garlic, onion, sugars, beef and other meat digests, and nonfat dried milk products. These ingredients may be blended with other raw materials prior to extrusion, or they may be incorporated by coating the surface of the final product by spraying, tumbling, or dipping. Flavor enhancers and other nutrients are often injected into the extruder itself. The decision to use these ingredients and where to introduce them into the process will greatly influence palatability.

\section{Raw material preparation}

The particle size of the raw materials will affect the texture and uniformity of the final product. The extrusion cooking process can utilize a broad spectrum of ingredient particle sizes. It is desirable, but not necessarily essential, that particles be of uniform size and density to prevent segregation during mixing and transport prior to extrusion. Most importantly, a uniform particle size promotes uniform moisture uptake and cooking during extrusion which prevents hard, partially cooked particles in the final product.

When whole grains are received into the manufacturing facility, they should be pre-ground to pass through an opening of 1000 micron or larger prior to mixing. The final formulation is then ground just prior to extrusion to achieve the desired final particle size. When die openings are three millimeter in diameter or larger, it is common for this final grinding step to be through a screen having $1.2 \mathrm{~mm}$ openings. With die openings smaller than 3-mm in diameter, the maximum particle size should be one-third the die opening.

\section{Selection of hardware}

The selection of processing equipment for a manufacturing plant is an important decision. Equipment that will give the highest operating efficiency and most versatility at the lowest total cost should be chosen. When sizing equipment for any plant, it is important to determine the rate or capacity at which the plant will be operating. The probability of future expansion must also be considered.

For example, it may cost very little extra to purchase a conveyor or storage bin that is capable of twice the presently needed capacity. The equipment in pet food, aquatic and livestock feed plants are required to perform the following 
functions: receiving, storage, grinding, mixing, conveying, extrusion cooking, drying/cooling, pumping, coating, and packaging.

The extrusion portion of the system includes a live bin/ feeder, preconditioner, extrusion cooker, and die/knife assembly. Each component is designed to accomplish a specific function in the process of cooking and forming products. The operating conditions can be adjusted to vary the characteristics of the finished product.

Feeder

The live bin/feeder provides a means of uniformly metering the raw materials into the preconditioner and subsequently into the extruder. This flow of raw material must be uninterrupted and rate controllable. The live bin/ feeder controls the product rate or throughput of the entire system. Variable speed augers or screw conveyors can be used to volumetrically meter ingredients into the system. These same devices can be designed and manufactured to act as loss-in-weight (gravimetric) feed systems by mounting the bin/feeder assembly on load cells and continuously monitoring its weight.

\section{Preconditioner}

Uniform and complete moisture penetration of raw ingredients significantly improves the stability of the extruder and enhances the final product quality. In addition, plasticizing the raw material particles prior to extrusion, the extruder wear caused by the abrasive raw material particles is greatly reduced.

In the atmospheric preconditioner, moisture is uniformly applied in the form of water and/or steam to achieve a moisture content of 10 to 25 percent. Water is introduced from the top of the preconditioner utilizing spray nozzles to atomize the water stream thereby reducing the mixing load on the preconditioner. Steam is added from the bottom and the supply plumbing must be designed to supply a continuous flow of condensate free steam.

Preconditioners, which have been used in the pet food extrusion process since 1960, contain one or two mixing/conveying elements which consist of rotating shafts with radial attached paddles. Atmospheric or pressurized chambers may be used in the preconditioning step. Pressurized preconditioners can achieve higher discharge temperatures but have the potential of higher nutrient destruction and higher operating costs. Mulenaere \& Buzzard (1969) reported losses of available lysine of 13 to 28 percent in a pressurized preconditioner compared to losses of only three percent available lysine in an atmospheric preconditioner.
Total moisture addition, product temperature, and retention time are all processing conditions that can be controlled to achieve desired results. Steam injection alone in a conditioning device will elevate the substrate moisture by no more than five to seven percent. Higher moisture levels are achieved by the addition of water. At moisture levels of 20 percent or below, the degree of cook in the preconditioned material will rarely exceed 20 percent. Several studies have indicated that a minimum of 30 percent moisture is required in feedstuffs to achieve complete gelatinization in the absence of shear. Steam and water flow rates are usually balanced to give a mixture temperature of 70 to $90^{\circ} \mathrm{C}$ at the preconditioner discharge.

Fresh meat, oil, flavors, coloring agents, and other liquid additives may be introduced at this phase of the process insuring thorough and continuous mixing of all the foodstuffs entering the extruder barrel. If fat is added in liquid form as a separate stream, the point of addition is critical to achieve cook while maximizing the level of fat. Fat is usually added near the discharge of the preconditioner to allow optimum preconditioning. Fat tends to coat individual feed particles hindering moisture absorption and the transfer of thermal energy to accomplish gelatinization. Extending retention times in the preconditioner is a useful tool to enhance gelatinization in high-fat formulas.

Cook is defined as the percentage of starch made susceptible to amyloglucosidase hydrolysis. When steam is added at a rate which exceeds 10 percent on a dry feed basis, considerable vapor loss occurs from the preconditioner to the environment. It must be noted that the first 120 seconds of retention time, when exposed to steam injected into an atmospheric pressure preconditioner, are the most important in making a significant contribution to the cook of the final product.

\section{Extruder}

As the material leaves the preconditioner, it enters the extruder barrel. Here the major transformation of the raw preconditioned material occurs which ultimately determines the final product characteristics.

The initial section of the extruder barrel is designed to act as a feeding or metering zone to simply convey the preconditioned material away from the inlet zone of the barrel and into the extruder. The material then enters a processing zone where this free flowing material is worked into amorphous dough. The compression ratio of the screw profile is increased in this stage to assist in blending water or steam with the raw material. The 
temperature of the moist dough is rapidly elevated in the final few seconds of dwell time within the extruder barrel.

Most of the temperature rise in the extruder barrel is from mechanical energy dissipated through the rotating screw. It may be assisted by the direct injection of steam or from external thermal energy sources. The screw profile may be altered by choosing screw elements of different pitch or with interrupted flights, or by adding mixing lobes configured to convey either in a reverse or forward direction. All of these factors affect the conveying of plasticized material down the screw channel and therefore the amount of mechanical energy added via the screw.

Steam injection into the extruder is also a contributing factor to cooking. This additional energy input results in capacity increases, more tolerance for high fat levels in the formulations, and reduced requirements for large drive motors.

This moisture addition and a properly configured extruder barrel will result in a final pressure of the extrudate prior to the extruder die of 34 to 37 atmospheres, a temperature of 125 to $150^{\circ} \mathrm{C}$ and a moisture content of 23 to $28 \%$.

\section{Single screw extruder}

The single screw cooking extruder has been the "heart beat" of dry-expanded pet food in the United States for over 40 years and it is the most used extruder model for aquatic and livestock feed as well. The screw and barrel configurations represent many years of analytical design, research, and comprehensive testing. A better understanding of the interaction between the machine and materials has led to the development of screw and barrel geometries for single screw extruders that are more efficient in converting mechanical energy to heat through friction.

These screws have increased volumetric capacity permitting higher levels of steam injection into the heads. The barrel segments may be ribbed to alter the function of each specific extruder segment.

\section{Die/Knife design}

The extrusion chamber is capped with a final die which serves two major functions. First, the die offers restriction to product flow thereby causing the extruder to develop the required pressure and shear. The final die also shapes the extrudate as the product exits the extruder. Die design and its effect on expansion, uniformity, and appearance of the final product are often overlooked.

The amount of expansion desired in the final product can be controlled by formula manipulation and open area in the die. Unexpanded but fully-cooked pet foods, aquatic and livestock feed generally require 550 to 600 square millimeters of open area per metric ton of throughput. Highly expanded foods require 200 to 250 square millimeters of open area per metric ton throughput.

Final dies may be as simple as single plates with a predetermined number of sized round openings, or they may consist of two or more plate elements. The first plate element of a two piece die serves to increase the resistance to flow and to aid in imparting shear to the extrudate. The second die plate in a two piece die is used to size and shape the extrudate by forcing it to flow through a number of orifices. Spacers may be added between the extruder barrel and the final die plate to even out the flow from the extruder screw to the final die plate and give additional retention time for cooking.

A recent development in die technology is the Back Pressure Valve (BPV). The BPV controls the restriction on the discharge of the extruder and allows for product diversion. By changing the restriction at the discharge of the extruder during operation, the product density can be varied by up to 25 percent without changing the screw configuration or the final die. The product diversion feature allows startup and shutdown waste to be diverted from the final die which keeps the die area from becoming contaminated.

A face cutter is used in conjunction with the die, which involves cutting knives revolving in a plane parallel to the face of the die. The relative speed of the knives and the linear speed of the extrudate results in the desired product length.

\section{Drying and cooling}

The primary purpose of drying is to reduce the level of moisture in an extrusion cooked product. In some cases, the drying process can involve additional heat treatment of the product. One example of this is the drying at elevated temperatures to impart a "baked" or "toasted" flavor and appearance to the product. However, as early as 1983, it was found that the production of dextrin during extrusion or drying may decrease palatability.

For dry expanded extruded products, the final moisture content needs to be less than 10 percent to prevent mold and bacterial growth. Water activity is the critical factor in determining the lower limit of available water for microbial growth. In general, if the water activity of a product is less than 0.65 no bacterial problems will occur, and if the water activity is less than 0.6 then molds can be prevented

As mentioned earlier, most pet foods, aquatic and livestock feed are best processed at extrusion moistures between 23 to 28 percent. Some of the moisture is lost due to flash evaporation as the superheated product exits the 
die and expands. Further moisture will be lost through evaporative cooling, as the product cools during conveying to the dryer. Pneumatic conveying of products from the extruder to the dryer inlet reduces product moisture content one to two percent. Pneumatic systems help separate sticky products that tend to clump with belt conveyors and improve sanitation around the extruder die.

Horizontal conveyor dryer is the most common drying equipment for most extruded products. In the horizontal conveyor dryer, the product is spread on a belt that moves through the dryer. Heated air is then passed through the bed of product at a velocity between 40 and 60 meters per minute and an air temperature of 90 to $180^{\circ} \mathrm{C}$. After the air is circulated through the product, a portion of it is exhausted to carry away the water removed from the product and the remainder is mixed with fresh incoming air, reheated, and then passed through the product again. These dryers can be single or multiple pass in design, depending on the configuration required to fit the plant location and to adequately dry the product. The horizontal conveyor dryer provides for excellent control of retention time and results in uniform drying.

There are a number of product factors that will determine how the product dries. The incoming product's moisture content, size, shape, and density will all alter its characteristic drying curve. Temperature, time, bed depth, and air velocity are all controlled within the dryer to accomplish both complete and uniform drying.

Drying curves are used to describe how a product dries. After being dried the product requires cooling before it is packaged. If the product is packed or stored in bulk without prior cooling, the moisture contained in the hot air and the residual moisture in the product will condensate on the container wall as the product slowly cools in the package or storage bin. This will result in the growth of mold and bacteria in the damp areas.

The cooler can be directly coupled to the dryer or can be a stand alone unit. When more than five to eight percent fat is applied as a coating to pet foods, the product is dried, coated before being cooled. In these instances, a vertical counter-flow cooler is used to avoid fat accumulation on the conveyors of a horizontal cooler.

After drying and cooling, it is important to screen out any small pieces or fines that may have developed during the drying, tumbling, and cooling operations. Those fines may be recycled back into the raw mix prior to extrusion so that no loss of product occurs. A properly operated system producing dry-expanded pet food, aquatic and livestock feed will average only between three to five percent fines.

\section{Coating}

Most dry-expanded extruded products for animals operations apply liquid fat and/or flavors after drying, cooling, and sizing to enhance the acceptability and palatability of their products. Where it is preferred that the drying and cooling modes be accomplished in separate pieces of equipment, these feedstuffs often are coated after drying but prior to cooling. This choice has the advantage of coating a warm product which improves absorption. Liquid fats and flavors are normally applied in revolving cylindrical reels by spraying a mist of liquid or sprinkling a dry powder over the product as it enters the rotating reel. The reels are heated to keep the fat from solidifying on the inner surface of the reel. Fat heating tanks, used as a surge for the fat addition system, normally have the capability of preheating the fat to $60^{\circ} \mathrm{C}$ which is the recommended temperature. A metering device is used to meter the dry extruded product into the rotating applicator reel to ensure that an accurate level of dry material is mixed with the added fat. When fat is added at percentages between one and five percent, a misting nozzle is normally used inside the fat coating reel. When applying higher percentages, a flood type nozzle is used.

Another coating device cascades the dry product through a "curtain" of liquid coating created by a spinning disc assembly. This eliminates the need for spray nozzles. Recently, high speed mixing machines have been utilized to uniformly apply liquids to pet foods. These machines load and discharge their contents rapidly to actually convert a batch process to a continuous-batch system. Liquids are "slugged" into the mixer and depend upon the tremendous particle movement to wipe it from particle to particle. Typical cycle times per batch are 5 to 30 seconds.

Vacuum infusion coating systems have several process benefits over atmospheric systems, such as up to a 40 percent liquid addition and the infusion of coatings into the pellet cell structure. Vacuum infusion draws coating liquids into all air cells within the extruded product while atmospheric processes result only in topical coating of the feed.

\section{Process control}

Due to the potential for economic benefit, the extrusion cooking process will continue to become more automated. Automation has provided the potential for reduced product waste, improved product uniformity, enhanced proficiency of operators, and process documentation, as well as reducing utility costs, improving safety, and providing the opportunity for prediction, monitoring, and control of product quality. Process control and automation removes 
the human influence and the inevitable product variability associated with the operation of the extruder.

Feed rates can be controlled by gravimetric feeding devices which can maintain accurate control \pm 0.5 percent of the desired dry feed rate. The gravimetric feed device continuously records the weight loss of the feed bin as a function of time. This weight loss rate is compared by the computer to the desired feed rate and the speed of the feeding screw is controlled. Steam and water flow rates to the preconditioner are also controlled by a process controller. Each flow can be controlled as a percentage of dry feed rate by a control valve. Steam and water flow rates for injection into the barrel can be controlled in similar fashion. Extruder head jacket temperature profiles can be controlled along with monitoring of the extruder motor load and die pressure. These parameters can be used to control the feed rate to prevent motor overloading while keeping the production capacity at a continuously high level.

Automation is moving towards the time when an operator will input the product quality requirements such as density, palatability, and digestibility and the control system will adjust processing conditions based on the recipe characteristics to give the desired results. Reaching this level of automation will require on-line instrumentation for continuous recipe and final product analysis.

\section{Final product specifications}

Many aspects of final product specifications have already been discussed. Exact specifications are set by the manufacturer as determined by the market. Final products are formulated first to meet the nutritional requirements for the animals' specific physiological stage of life. Economic considerations are generally guided by least cost formulation techniques. Storage and shelf-life qualities become the next concern and are achieved partially through formulation, but they are also controlled by processing and packaging techniques. Size, shape, color, and other physical attributes are also important considerations. Certain physical characteristics built into a product often become the standard by which the consumer identifies a particular manufacturer's product.

\section{Quality control}

The quality of extruded pet foods, aquatic and livestock feed is important and control of that quality is a must. To be acceptable and to meet the standards expected by consumers, manufacturers must ensure that their products are nutritious, palatable and provide the highest feed conversion. The importance of selecting high quality raw materials cannot be overstated and sampling and monitoring of that quality is of equal importance. When quality ingredients are formulated into a nutritious, balanced diet, their quality must be preserved with proper processing.

Proximate analysis and other analytical tests are performed on the final products to confirm their nutritional values. There are many methods used to determine if the starchy portions of extruded product are properly cooked or gelatinized. The experience of operators is also a valuable tool to ensure the quality of these foods.

In a plant situation, visual inspection of a product during processing can permit a rapid response by adjusting the processing variables to maintain quality standards. Returning to a set of processing conditions known to yield a desirable end product is possible only if accurate and complete records are maintained. However, it is difficult to visually assess all aspects of product quality and for this reason several test methods have been developed to assist in quality control.

A water absorption test is often used to quickly determine the rate and amount of water absorbed by dry foods. It is applied to the final product after post extrusion drying and cooling. A method used to monitor cooked starch in products is an enzyme susceptibility test which mimics the digestion in the internal tracts of animals. Since this test requires two hours to complete, it is typically used to spot check or monitor production lots rather than to serve as an on-line quality control tool.

Starches can be overcooked to the point that they are dextrinized. That may be important to palatability, as dogs can detect subtle levels of dextrins that are below the visual stages of scorching. The most common cause of this phenomenon is the over-drying of foods at high temperatures and long residence times resulting in Maillard browning reactions. Maillard products need not be monitored if pet foods are carefully dried to moisture levels safe for storage.

Controlling product appearance is dependent upon two variables - processing conditions and formulations. Measuring the bulk density of foods at various points along the process flow is a good, quick, reliable quality control method. Bulk density determines "bag fill" and reflects how well the product is cooked or expanded. Typical dry-expanded pet and aquatic foods have densities in the range of 280 to 400 grams per liter. Expanded pet and aquatic foods will often expand by more than 50 percent of the die opening. The degree of expansion is positively affected by the level of starch and soluble protein and will be negatively affected by the level of fat in the formulation.

Monitoring the moisture content of the final product is extremely important to ensure stability during storage. The maximum moisture content for dry expanded foods is 12 percent. Automation in the field of moisture monitoring has 
progressed rapidly with the implementation of continuous, on-line "moisture meters." Those instruments are placed at strategic locations along the process flow to monitor moisture contents. Dryer temperature, air flow, and retention time may be slaved to on-line instruments measuring moisture in the final product. Other techniques involve measuring relative humidity in the dryer exhaust air and using that variable to assist in control of the final product moisture.

Water activity $\left(\mathrm{A}_{\mathrm{W}}\right)$ indicates the amount of water in a total sample that is available to microorganisms. Measurement of $A_{\mathrm{w}}$ involves placing a sample of food in a hygrometer which is an enclosed chamber containing a humidity sensor (Fontana, 1998).

Feeding trials to determine palatability and digestibility can be utilized to characterize product quality. These tests are time-consuming and expensive, but are the most reliable barometers of product quality.

Strahm et al. (2000) describes the use of the Phase Transition Analyzer ${ }^{\circledR}$ (PTA) as a tool to determine the effects of temperature and moisture on the phase transitions of pet food and aquatic recipes. This application of Food Polymer Science is useful in understanding the effects of extrusion/drying/cooling processes.

\section{Trouble shooting techniques}

If it is desirable to lower the bulk density of extrusion cooked foods, the following processing variables may be altered as described. Since the recipe has the single largest impact on density, one should keep in mind that these changes are subject to the formulation as not all formulations will react in the same manner.

Moisture content: generally, lowering the water content injected into the product without decreasing the steam level added to the product will assist expansion. However, when extruding formulations containing high protein (above 23 percent) or high fat (above 5 percent), it is actually necessary to increase total moisture by adding both steam and water. Once the moisture level in the extruder barrel drops below 20 percent further decreases in moisture will result in increases in product density.

Increasing the dry feed throughput will in effect reduce the open area in the final die per unit of throughput. This reduction in open area results in greater expansion. As the feed rate is increased beyond a certain point the density begins to increase due to the loss of retention time in the preconditioner and extruder barrel.

The mechanical energy input can be adjusted by changing the extruder screw speed, final die setup, or screw profile. Higher screw speeds, less open area in the final die, and the addition of cut-flight screws or shear locks all will add additional mechanical energy and decrease bulk densities.

Increasing the residence time in the preconditioner and the amount of steam added to the product at this point will assist in cook and expansion. The residence time in the preconditioner can be increased by changing the paddle configuration, adding a residence time control package, or lowering the throughput.

Steam injection in the extruder barrel: Injecting steam directly into the product along the extruder barrel will tend to lower the bulk density.

Addition of oil will increase product densities. In general, for each one percent of fat above 12 percent, the bulk density of the final product will increase by up to 16 grams per liter. Once the total fat content in the extruder barrel exceeds 22 percent, product durability is difficult to maintain and could result in excessive fines. Typically as the fat level increases, the moisture must be increased as well for adequate processing.

When it is desirable to extrude a product having a smooth surface, there are several adjustments that can be made to the processing conditions and die configuration. Moisture contents too low during processing will cause the product to texturize on the outer surface as it passes through the die orifice. The lower moisture content reduces lubricity and retards the flow of material. The product in the center of the die orifices will tend to flow faster. Moisture contents can be excessively high (greater than 35 percent) resulting in a wet dough that is not completely gelatinized and is too moist to hold a firm shape. Reducing the temperature in the last section of the extruder barrel may be necessary to help reduce sticking on the surface of the die orifice. If the inside surface of the die orifice is rough or is excessively long, a rough outer surface on the product can result.

Improper knife blade adjustments or badly worn die surfaces may be responsible for "tails" on the product. Tails or protrusions are exaggerated with kibbled or other product shapes having delicate points or extensions and are often separated from the main product chunk during handling and storage resulting in an excessive amount of fines.

Fines in the final product can also be the result of poorly cooked foods that are fragile and have little cohesion or binding strength. Any fines generated through the processing of extruded foods should be removed prior to packaging by passing the final product over screening devices. A phenomenon known as “wedging” often appears 
in expanded products that are extruded at temperatures that are too high just prior to the die or where the throughput or feed rate of the dry ingredients exceeds, or in considerable less than, the open area or capacity of the die openings.

Corrective measures can also be made to improve product appearance by adjusting formulations prior to extrusion cooking without compromising nutritional considerations. Higher fat contents reduce the generation of fines with all other variables being constant. If a formulation contains high protein and fat levels, extrusion moistures and temperatures should be elevated to compensate for those changes. Experience has shown that a useful guideline is to add 0.6 percent water in the preconditioner and 0.4 percent steam injection into the product the extruder barrel for every one percent increase in protein above 23 percent.

\section{Evaluation of operational costs}

The extrusion cooker offers very affordable and efficient continuous cooking opportunities for many products. An economic prediction must be made on each product to determine the potential for profit. The input of raw material cost, energy cost, and capital equipment cost as related to the extrusion module should be considered. Economic analysis of the entire plant and all equipment specifications for the production of extruded products is a detailed and complicated subject that must be completed with a manufacturer's specific needs in hand.

Raw material costs have the greatest impact on total operational expenses. It should be remembered that ingredients coming into the production plant usually are usually between 10 to 13 percent moisture and the feeds being sold are typically between 8 to 10 percent moisture. There is an immediate shrinkage by weight and a corresponding economic loss. Waste from startups, shut downs, and continuous operation also contribute to product shrinkage. As a rule of thumb, five to seven percent product shrinkage in a dry pet food plant is considered to be excellent. It is essential to select equipment for each unit operation that will minimize waste.

The cost of energy for processing is critical to the economic performance of any extrusion plant. A typical plant will consume energy from electricity, natural gas, or oil. Energy cost is important because it will influence profit. A one or two percent change in formulation cost will have over a 20 times greater effect on profit than will a similar change in utility costs. The labor costs for an extruder/dryer manufacturing cell are also minimal. One operator can manage two complete lines from extruder inlet to dryer discharge or one operator can effectively manage four extruders per cell if a second operator is in charge of the dryers. Labor costs will generally always be less than expenditures for utilities.

\section{Conclusions}

Extrusion cooking for the production of many products has come of age within the past three decades and provides a very useful and economical tool for processing animal diets. This process permits better utilization of available cereal grains and vegetable and animal proteins to permit cost effective and nutritionally sound diets with improved and unique feeding characteristics.

Palatable, functional, and tailor-made feedstuffs can be profitably manufactured management of raw material formulation, system configuration, and processing conditions. The extrusion cooker can be used to develop profitable and nutritional products using ingredients which were previously underutilized or poorly accepted.

\section{References}

FONTANA, A.J. Water activity: why it is important for food safety. In: NSF INTERNATIONAL CONFERENCE ON FOOD SAFETY, 16., 1998, Albuquerque, NM. Proceedings... Albuquerque: 1998. (Apresentação em Powerpoint).

HOSENEY, R.C. Estimation of degree of cook (Measurement of starch gelatinization). In: McELLHINEY, R.R. (Ed.) Feed manufacturing technology IV. Arlington: AFIA, 1994. p.560-561.

MULENAERE, H.J.H.; BUZZARD, J.L. Cooker extruders in service of world feeding. Food Technology, v.23, p.345-351, 1969.

ROKEY, G.J.; ABERLE, R.A. Advanced processing. Petfood Industry, v.43, n.2, p.4-6, 2001.

STRAHM, B.; PLATTNER, B.; ROKEY, G. et al. Application of food polymer science and capillary rheometry in evaluating complex extruded products. Cereal Foods World, v.45, n.7, p.300-302, 2000

TEETER, W.A. Carbohydrates for dogs. Pet Food Industry, v.21, p.3-25, 1979. 